\title{
Arte Educação Para a Cidadania: emergência de um discurso político para a arte educação no ensino formal em Portugal e na Europa
}

\author{
Art Education and Ccitizenship: emergence of a \\ political discourse in formal education in Portugal and Europe
}

Teresa Torres Eça

\begin{abstract}
The article starts from two key documents to discuss curricular discourses of art education in Europe: the 2009 European Report of the Education, Audiovisual and Culture Executive Agency and the 2013 Report of the Portuguese National Council of Education about media education. The discussion points out the increasing disinterest in critical education and claims to a more committed role of art education in the curriculum of public schools for more democratic educational systems.

Keywords: Art education - Curriculum. Citizenship education. Digital literacy.

Resumo: Parte - se, neste artigo, de dois documentos chave para discutir discursos curriculares de arte educação na Europa: o Relatório europeu da Education, Audiovisual and Culture Executive Agency de 2009 e o Parecer do Conselho Nacional da Educação de Portugal, emitido em 2013 sobre a educação para os mídia. O cerne da discussão aponta para o crescente desinteresse pela educação crítica apelando para um discurso mais comprometido sobre o papel da arte educação no curriculum das escolas públicas para uma oferta educativa verdadeiramente democrática.

Palavraschave: Arte educação - Currículo. Educação para a cidadania. Democracia - Literacia digital.
\end{abstract}

\section{Educação}

E

ducação e aprendizagem não são sinónimos. Por educação normalmente entendemos sistemas normativos; de formatação, de consciencialização e de desenvolvimento de capacidades de ser, estar e agir com vista ao desenvolvimento harmonioso do individuo e da sociedade. Normalmente entendemos o conceito 'educar' como uma oferta, uma relação entre pelo menos duas pessoas, onde existe um processo facilitador para ajudar a desenvolver o que há de melhor em cada um.

A aprendizagem não é uma oferta, é um processo pessoal de aquisição de saberes durante o percurso da vida, estamos sempre a aprender em todo o lado e com tudo o que nos rodeia. Apren- 
dizagem, sendo um processo autoregulador, não responsabiliza nenhuma política ou comunidade, é um processo de procura individual. Aprender é tão natural como respirar e a nossa sobrevivência como espécie depende do que aprendemos através de experiências vividas e das nossas capacidades de manipular informação. Mas, a nossa sobrevivência como sociedade e como planeta depende dos processos educativos que temos, tendo a educação um papel "[...] ético na compreensão planetária [...]" (MORIN, 1999, p. 83). Segundo Morin, o objetivo essencial da educação deveria ser "[...] civilizar e solidarizar a terra, transformar a espécie humana em verdadeira humanidade [...]" (MORIN, 1999, p. 83). A educação deveria ajudar os cidadãos a aprender uma "[...] ético na compreensão planetária [...]" (MORIN, 1999, p. 83) tornandose aberta à diversidade e procurando cimentar a cidadania democrática.

A sobrevivência do nosso planeta habitável para seres humanos e outras espécies, hoje mais do que nunca, depende da educação que estamos a proporcionar aos indivíduos, quer sejam, crianças, jovens ou adultos.

No entanto, na prática, os sistemas educativos formais, tais como o ensino nas escolas públicas desde o ensino fundamental à universidade, estão quase sempre associados a valores de mercado e não a valores de conservação do planeta e das espécies. Neste século, estes sistemas educativos formais parecem estar associados à competição mercantilista de curto prazo e não ao desenvolvimento harmonioso do ser humano e do planeta a longo prazo. Na verdade, até o termo educação está cada vez mais em desuso. Ângela Saldanha, na sua tese doutoral No Caminho Para Casa, refere que em documentos europeus chave como o Memorando Sobre a Aprendizagem ao Longo da Vida (COMISSÃO DAS COMUNIDADES EUROPEIAS, 2000) o termo aprendizagem é referido 17 vezes e o termo educação é apenas referenciado uma vez. Ângela escreve:

Os perfis dos alunos estão bem referenciados nos tratados europeus e na cimeira de Lisboa. A Europa tenta unificarse numa identidade própria e tenta acabar com as artes, humanidades, tudo aquilo que identifica os países. Os alunos vão para as ciências e as tecnologias para estarem aptos a trabalhar em toda a Europa. Perdemse as identidades e os valores alteramse, perdendose ou alargando as raízes. (SALDANHA, 2014, s/p.)

Este comentário de uma jovem investigadora em educação artística de Portugal põe o dedo na ferida atual da dicotomia global/local. O fator globalizante mercantilista das sociedades leva à perda de identidades e de valores locais e humanitários defendidos pela educação progressista que apontava, no século passado, para a educação para a cidadania. Essa perda de identidade e de humanidade é acentuada por diretivas centradas nas competências de mercado, em sociedades que só valorizam o dinheiro como fator de sucesso e se regem apenas por bitolas de um sector bancário que regula toda a política no mundo. Nesta visão neoliberalista do mundo a educação para a cidadania crítica, progressiva e democrática não tem lugar. Apenas interessam aprendizagens muito específicas para que os consumidores adquiram competências e literacias eficazes na produção, transação e consumo rápido de bens materiais independentemente das consequências ambientais desse consumo. 
No final da primeira década do século vinte e um, em Portugal viviase ainda um entusiasmo crescente pela educação como fator de transformação social, influenciado por pensadores como Selby, Freire, Morin e Delors. Pensavase que o acesso ao conhecimento, a melhoria dos problemas universais, a total integração na sociedade moderna, passaria necessariamente por uma educação mais global (SELBY, 2002), atenta a fenómenos de exclusão, e à inclusão de uma educação para a cidadania e aprender na cidadania. Assim, a educação deveria "[...] ajudar a compreender o mundo e o outro, a fim de que cada um se compreenda melhor a si mesmo [...]" (DELORS et al., 1996, p. $50)$.

A nível de investigação em educação, estes discursos continuam ainda vigentes na área das ciências sociais e formação de professores, por exemplo, na tese de Ilda da Purificação Freire Ribeiro, defendida na Universidade do Minho em outubro de 2010, a doutoranda advoga:

Acreditase que o renovado papel da educação requer uma formação profissional que contribua para o elevar do nível educativo de todos e para a proliferação de cidadãos capazes de participarem activamente num projecto comum a todos os cidadãos. Ora, é aqui que confluem a educação e a cidadania, fazendo emergir a necessidade de uma educação para a cidadania em ambiente escolar. (RIBEIRO, 2010, p. 440)

\section{Experiências}

Certo! Podemos sempre continuar a ter discursos utópicos, devemos sobretudo continuar a ter atitudes utópicas para combater a depressão generalizada pelas consequências do neoliberalismo económico na educação. Mas convém estar conscientes do enorme fosso que existe entre discurso e prática educativa. Para Jorge Larossa, ao largo de toda a nossa travessia

[...] pelos aparatos educacionais, estamos submetidos a um dispositivo que funciona da seguinte maneira: primeiro é preciso informarse e, depois, há de opinar, há que dar uma opinião obviamente própria, crítica e pessoal sobre o que quer que seja. Com isso, nos convertemos em sujeitos competentes. (LAROSSA, 2002, p. 21)

Mas, dar opiniões sobre qualquer coisa, não é sinónimo de conhecer!!!! Com o ênfase generalizado na sociedade da informação e na celeridade das trocas de informação esquecemos que a informação por si só não é fonte de conhecimento. São apenas dados que podem ou não ser recolhidos, analisados, selecionados com vista a nos ajudar a melhor compreender um fenómeno, conceito ou situação. Na verdade temos modelos educacionais perversos e acelerados que não valorizam a experiência como conhecimento, os aparatos educacionais que temos no ensino formal funcionam cada vez mais no sentido de nos tornar apáticos consumidores de informação, com ausência de qualquer paixão em termos de experiência do conhecimento verdadeiramente significante. E nesse contexto, sendo as artes um campo e conhecimento predominantemente emocional e experiencial, não existem muitas opções para as artes na educação no sentido da educação pela arte, ou seja o 
acesso aos processos e produtos artísticos para todos. Apenas resta algum espaço, no que respeita o acesso ao ensino especializado da arte para uma elite, para a formação de artistas e fruidores de arte. Mas isso não corresponde ao sentido da educação pela arte, que surgiu no pós segunda guerra mundial pela mão de Herbert Read, fundador do movimento de arteeducação no mundo, e que ainda hoje é proclamado pelos membros da Sociedade Internacional de Educação pela Arte (InSEA). Os membros da InSEA acreditam que a Educação através das artes constitui um meio natural de aprendizagem em todas as etapas do desenvolvimento do indivíduo, promovendo valores e disciplinas essenciais à formação plena, tanto a nível intelectual como emocional e social dos seres humanos de uma comunidade.

\section{Arte Educação}

A arte educação é um território entre fronteiras, apesar de se referir a um domínio do conhecimento único: a educação através das artes é suficientemente transversal para atravessar lugares diferentes de pratica e teoria. Creio que se entendermos a educação, no seu sentido lato de preparação para a vida, as artes e o ensino através das artes sempre couberam nessa tarefa desde os primórdios da humanidade. A dança, a música, a poesia; a narração de estórias, a criação de imagens e de objetos nos mais variados aspetos e artefactos das artes visuais foram nas sociedades préhistóricas e continuam a ser, em muitas comunidades, meios educativos para as crianças, os jovens e os adultos entenderem e construirem as suas culturas e identidades.

A educação formal e informal, como as entendemos hoje, são fenómenos recentes na história da humanidade. Muito se tem escrito sobre os propósitos da educação formal que tende a instruir; treinar; preparar indivíduos para o mercado de trabalho; discriminar; nivelar; regular e normalizar sociedades em nome do progresso; igualdade de oportunidades e rentabilidade económica. Como estabelecemos no início deste artigo, desde o final da década de noventa do século vinte temse agravado cada vez mais o pendor economicista e discriminatório na educação. Vemos hoje nos sistemas educativos a supremacia dos campos da ciência e da tecnologia em detrimento dos campos humanistas do conhecimento que dificilmente são avaliados por sistemas nacionais ou internacionais de comparação de resultados escolares. Dentro dessa visão reguladora da educação, a arte educação tem um papel definido, na formação geral de indivíduos e na formação especializada. Esse papel é reconhecido pela maioria dos sistemas educativos (EACAE, 2009). Na formação geral dos indivíduos destacase a educação para a arte, no sentido de formar públicos capazes de compreender para fruir e ou consumir objetos culturais, tais como obras de arte, imagens, filmes, vídeojogos, música, etc. Na formação especializada destacase o ensino da arte para formar produtores culturais capazes de trazer benefícios económicos, tais como por exemplo os profissionais das chamadas indústrias criativas .

O discurso dos arte educadores, no entanto, centrase sobretudo na contribuição transversal da arte na educação, na sua capacidade de desenvolver educação para a paz, para a cidadania, para a educação sustentável devido às características únicas dos processos artísticos que facilitam a exploração de inteligências; apetências e capacidades multidisciplinares. Segundo Eurydice, base 
de dados sobre sistemas educativos europeus, os objetivos gerais da arte educação são, em geral, bastante semelhantes entre os países europeus: todos ou quase todos os países mencionam "habilidades artísticas, conhecimento e compreensão", "apreciação crítica, apreciação do património cultural", expressão individual/identidade, "diversidade cultural e criatividade" como objetivos. Segundo a Education, Audiovisual and Culture Executive Agency (EACAE), na grande maioria dos países das Comunidades da União Europeia, a educação artística visa também o desenvolvimento pessoal e emocional, uma vez que promove habilidades sociais e realização pessoal através de experiências de prazer e satisfação (EACAE, 2009). No estudo da EACAE de 2009 foram abordadas algumas questões interessantes como a organização e os objetivos do currículo de artes, formação de professores, avaliação, participação de artistas profissionais, a utilização das TIC na educação artística, e artes como atividades extra curriculares . Abordaremos de seguida a primeira e a última questão à luz desse estudo.

\section{Qual é o Lugar da Arte nos Currículos Nacionais da Comunidade Europeia?}

Várias pesquisas têm argumentado que a arte educação tem um status relativamente baixo no currículo, tal facto foi também encontrado no recente relatório da InSEA sobre o currículo das artes visuais em 12 países $^{1}$ (MILBRANDT; EÇA; HSIEH; SHIN, 2014). Na Europa a arte educação pode ser agrupada e vista como um todo (o que acontece muitas vezes no ensino primário), ou como disciplinas separadas (o que acontece no ensino secundário). Normalmente existe mais oferta em educação das artes visuais e em Educação Musical do que nas outras artes (dança, drama) no ensino geral para todos os alunos. Em relação às outras disciplinas as artes ocupam muito menos tempo, excepto nos cursos vocacionais ou profissionalizantes das artes. Alguns países incluem o estudo do património e artesanato em seu currículo de artes obrigatório. Vários países também oferecem disciplinas separadas de multimídia, de história de arte e de arquitetura como parte do currículo (EACAE, 2009).

Segundo o relatório da EACAE (2009), em termos de tempo dedicado às artes, cerca de metade dos países europeus dedicam entre 50 e 100 horas por ano para as artes no nível primário e entre 25 e 75 horas por ano no nível secundário. No nível primário, este é certamente menos do que o tempo previsto para o ensino das línguas, matemática ou ciências. No nível secundário inferior, o tempo destinado a indivíduos de artes também diminui em comparação com as outras áreas. No entanto, existem variações consideráveis entre os países. Além disso, vários países permitem que as escolas tenham um currículo flexível dentro de um período de tempo mais longo que abrange dois ou mais anos, e outros dão às escolas autonomia para decidir a quantidade de tempo a ser dedicado a cada disciplina. Em termos de avaliação dos resultados dos alunos, em todos esses países - com poucas exceções - os resultados obtidos pelos alunos nas disciplinas artísticas tem pouco peso no seu sucesso escolar.

\footnotetext{
${ }^{1}$ Relatório elaborado por Melody Milbrandt, Teresa Torres de Eça, Kevin Hsieh e Ryan Shin apresentado na conferência mundial da InSEA, em Melbourne em Julho de 2014.
} 
Quanto ao papel das artes nas áreas transversais, esse papel não é muito explícito nos discursos curriculares, embora na prática educativa as artes sejam as primeiras disciplinas a veicular valores e atitudes para a educação cultural a educação para a cidadania, a educação para a paz e sustentabilidade, educação sexual e educação para os mídia. Apenas cerca de um terço dos países incentivam essas ligações transversais. Quando esse incentivo existe, ele pode ser um objetivo de todo o currículo ou um programa transversal ao currículo específico (por exemplo, educação cultural), ou pode ser encontrada dentro do próprio currículo das artes. Em alguns casos, a promoção multidisciplinar e transdisciplinar é declarada explicitamente como um objetivo do currículo de artes.

Com o virar do milénio muitas das nossas crenças foram questionadas, a crise económica que se iniciou nos países do Sul da Europa e que parece alargarse agora ao resto do continente; os desequilíbrios políticos entre Este e Oeste; Oriente e Ocidente; fundamentalismos; nacionalismos exacerbados e crescente influência de movimentos intolerantes e beligerantes trouxeramnos um clima de instabilidade, de medo e de falta de esperança no futuro. Também a nível ambiental o que observamos hoje com o aquecimento global, os seus efeitos visíveis no Pólo Norte e nas alterações climáticas mundiais não nos pode deixar indiferentes, como arte educadores deveremos recolocar as questões da justificação da arte educação no currículo, e sobre a maneira como queremos veicular os conteúdos da arte educação face a temas transversais que se devem reforçar na educação.

\section{Quais São os Objetivos da Arte Educação nos Discursos Curriculares Eu- ropeus?}

Existe um considerável grau de acordo entre os países europeus sobre os objetivos fundamentais da arte educação. Considerase que as artes são importantes no desenvolvimento dos jovens para explorar habilidades artísticas e oferecer conhecimentos e compreensão das artes. A maioria dos programas educativos também aponta o desenvolvimento de apreciação crítica; compreensão da cultura, do património e diversidade cultural; expressão individual; e criatividade (imaginação, resolução de problemas e tomada de riscos). Outros objetivos comuns são as habilidades sociais e habilidades de comunicação através de variedade de formas de arte e mídia. Alguns objetivos como desenvolvimento de autoconfiança/autoestima; promoção da aprendizagem ao longo da vida através das artes; e identificação de talento artístico estão presentes em apenas alguns países. Nas orientações curriculares gerais podemos encontrar por vezes objetivos de aprendizagem gerais e comuns que podem ser ligados à educação artística e cultural, por exemplo aprendizagem sobre a herança e diversidade cultural, bem como o desenvolvimento de expressão individual (EACAE , 2009).

Nas conclusões do seu relatório sobre arte educação para o Centre for Educational Research and Innovation (OECD), E. Winner, T. Goldstein e S. VincentLancrin referem que os discursos sobre a educação artística, objetivos e impactos esperados, precisam ainda de muita investigação para serem demonstrados e validados (WINNER; GOLDSTEIN; VINCENTLANCRIN, 2013). Para este autores não está claro que exista um impacto direto da arte educação nos resultados escolares dos alunos nas outras áreas do saber. Também não me parece que essa questão seja fundamental para a arte educação, ou que seja de alguma maneira relevante. Winner, Goldstein e VincentLancrin (2013), embora não possam proválo, acreditam que o ensino das artes é fundamental porque: 
As vidas das pessoas são infundidas com as artes enquanto ouvem música em seus iPods, lêm novelas, frequentam museus, assistem a peças de teatro e peças de televisão, assistem a espetáculos de dança, etc. Acreditamos que o bemestar e felicidade dos indivíduos será maior nos países em que as artes têm um papel de destaque nas nossas escolas, por causa do prazer inerente adquirida com as artes [...]. (WINNER; GOLDSTEIN; VINCENT-LANCRIN, 2013, p. 21)

E assim, os autores justificam os objetivos ligados à compreensão e fruição de objetos artísticos e culturais. Não me parece que seja uma justificação pertinente nem rigorosa e temo que em vez de reforçar o papel da arte educação nas escolas, declarações como estas apenas aumentam a precariedade da arte educação no currículo. No relatório os autores também falam da importância da educação das artes como meio para produzir consumidores de indústrias culturais e como meio para formar profissionais das indústrias criativas e de entretenimento. Declarações que estão em linha com a ideologia dominante dos construtores de currículo. No entanto, em última instância, e como razão maior para os objetivos da arte educação, os autores reconhecem que as artes permitem uma maneira diferente de compreensão, uma maneira que as ciências e outras disciplinas académicas não podem proporcionar. Porque as artes não funcionam com respostas certas e erradas, elas libertam os alunos para explorar e experimentar e são também um lugar de introspeção e de encontro de significados pessoais (WINNER; GOLDSTEIN; VINCENTLANCRIN, 2013). Esta última declaração é a que, na minha opinião, tem mais interesse para a permanência da arte educação no currículo para todos os alunos. As artes chamam a atenção para a nuance, a ambiguidade e a complexidade da vida. Ajudam as crianças e os jovens a aprender ideias e valores culturalmente importantes. As artes desenvolvem capacidades criativas e comunicativas construindo visões do mundo a partir de uma reflexão consciente sobre valores espirituais, estéticos, morais e cívicos.

\section{Literacia Digital e Educação Artística}

Nesta parte gostaria de discutir até que ponto a educação artística deveria estar mais atenta à educação para os mídia e literacia digital.

A utilização das TIC nos currículos de artes é incentivada em muitos países da Europa como um eixo transversal e / ou pode ser explicitamente fazer parte do currículo das artes (EACAE, 2009). Algumas disciplinas de artes são mais propensas ao uso das TIC, como artes visuais, estudos de mídia e música, mas de um modo geral podemos dizer que existe uma grande interesse na literacia digital em todas as áreas. No segundo congresso Português de Literacia, Media e Cidadania, em maio de 2013, foram amplamente debatidos temas como a exclusão ou inclusão social que advém do uso das tecnologias, o impacto dos computadores nos mais novos, a potencialidade para a participação cívica. Em Portugal houve um grande esforço a nível de escola pública para integrar as TIC nas escolas, nomeadamente a partir do final dos anos noventa e principio da primeira década do século vinte e um com o programa governamental chamado Plano Tecnológico para a Educação. No entanto o enfoque das TIC nas escolas públicas sempre foi sobre a manipulação passiva das tecnologias, o uso 
de produtos (software quase sempre licenciado nas disciplinas de artes) e não a sua produção livre (programação e aplicações de código aberto). Embora existam movimentos que reclamam o uso de produtos Open Source a população em geral, e a maioria dos professores de arte portugueses não estão sensibilizados para a promoção de uma sociedade de cultura livre no que respeita as TIC. Isto pode prenderse com fatores económicos muito potentes e também com um problema antigo de educação para os midia e de preocupação com a literacia digital:

Na verdade, uma educação a este nível não tem sido uma prioridade para as entidades governamentais, independentemente da orientação politicopartidaria. A educação para os midia tem colhido pouca atenção e interesse. Inserida muitas vezes, e apesar de tudo com sentido, na educação para a cidadania, tem tido dificuldade em afirmarse ao nível da acção pedagógica, cultural e política. (PINTO, 2011, p. 150)

Promover a literacia digital implica a execução de políticas estratégicas mundiais nesse sentido, e salientamos aqui o Programa para a Comunicação e Informação da Organização das Nações Unidas para a Educação, Ciência e Cultura (UNESCO) como um impulsionador do debate neste campo. Mas não estarão as questões da literacia digital, do acesso às Tecnologias da Informação e da Comunicação (TIC) e da educação para os mídia ligadas a um objetivo muito mais alargado onde o papel da arte educação pode ser muito maior?

"No documento Recomendações 'Sobre a Política de Educação para os Media', de 2007, o Conselho da Europa reconhece que nos últimos anos, este tema foi muitas vezes associado às questões das TIC, " [...] mas para o Conselho da Europa, estas questões estão fundamentalmente ligadas aos direitos do homem [...]" (PINTO, 2011, p. 46). Nesta linha de atuação o Conselho Nacional e Educação de Portugal reconhece que a "Educação para os Media como um meio de formar cidadãos capazes de forjar as suas próprias opiniões baseadas em informações obtidas através dos media, quaisquer que sejam os suportes". (PINTO, 2011, p. 46)

Neste sentido, a arte educação tem um papel importantíssimo, tendo em conta que grande parte da informação é hoje veiculada através de imagens estáticas, imagens em movimento e som. E que se torna urgente oferecer aprendizagem de conhecimentos sobre tais mídias para formar cidadãos críticos, conscientes e capazes de exercer livre arbítrio nas suas escolhas. $\mathrm{O}$ acesso às redes e plataformas digitais onde grande parte da informação é veiculada é muito mais do que a mera provisão ou fornecimento de um serviço aos potenciais utilizadores, suscitando complexos problemas do ponto de vista sociocultural e político (LIVINGSTONE, 2003). E, por outro lado, a disponibilização da informação online não basta, se não se investe igualmente na formação para a produção e acesso a vastos volumes de informação. Nas palavras de Livingstone, a capacidade de ajuizar e discernir, na análise da informação acessível, entre o que é rigoroso e o que é enviesado, o confiável e o suspeito é "[...] crucial para a literacia [...]" (LIVINGSTONE, 2003, p. 12) e para a sua abordagem numa perspectiva crítica e requisito para a promoção de uma cidadania crítica. Neste sentido as artes podem através de processos artístico criticoreflexivo trazer ferramentas essenciais. 


\section{Fragilidades}

Mais do que uma questão de fosso digital, o que nos acontece hoje na Europa é um problema de ignorância instrumental. Sem sabermos os processos básicos de produção de informação veiculada pelos mídia dificilmente poderemos gerir informação com liberdade.

$\mathrm{E}$, a compreensão dos processos de produção passa obrigatoriamente pela aprendizagem das artes. E se tal for reconhecido, as grandes fragilidades do ensino da arte como o seu status relativamente baixo no currículo; a falta de tempo e de recursos podem ser ultrapassadas. No entanto, precisamos reiterar aqui que estamos a falar de um conceito de artes contemporâneas, de arte educação multimodal atualizada feita por professores e educadores competentes e engajados na arte educação como educação para a cidadania e sustentabilidade. Muito ainda há que fazer para preparar tais professores e educadores tanto na formação inicial de professores como na formação ao longo da vida. Nesse sentido existe uma grande fragilidade na formação que se oferece aos professores de arte, a formação corresponde a modelos de escola e da arte anacrónicos, a uma visão do mundo afastada da realidade das crianças e dos jovens.

Perante uma crescente multiplicação da informação disponível e da expansão das indústrias do entretenimento a realidade dos portugueses (e dos Europeus) mudou consideravelmente. Em plena crise o uso de mídia não se refreou, pelo contrário, aumentou. E os discursos políticos e escolares acentuam a importância do uso de ferramentas para receber informação, para aumentar o consumo e uma economia que parece destinada à autodestruição num ciclo vicioso de consumo acrítico e insustentável.

\section{Práticas de Arte Educação}

Se por um lado cada vez mais se houve falar em trabalho de projeto, tal como é o tópico recorrente dos congressos anuais de professores de artes visuais Matéria Prima conduzidos pela Faculdade de Belas Artes de Lisboa, os discursos continuam a centrarse na arte educação disciplinar, um conhecimento sobre uma área, Art for Art Sake como se enuncia no relatório da OECD de 2013. Nos congressos de Educación Artística y Visual levados a cabo na Andaluzia, o ambiente é outro, entre o primeiro realizado em Sevilha e o último realizado em Jaén em 2012 as conversas giram à volta da arte educação como motor de transformação de atitudes, de mentalidades, como crítica e intervenção social. Neste contexto os objetivos para a arte educação viramse para horizontes cada vez transversais onde a arte como expressão, comunicação é além de processo de reflexão crítica um processo de intervenção social. Esta ideia vai a par com os movimentos de arte contemporânea ativista que têm surgido cada vez mais na cena cultural da Europa. As próprias demarcações entre as várias artes se esbatem no conceito híbrido das artes contemporâneas. As fronteiras entre artes performáticas e artes visuais e plásticas são cada vez mais ténues e isso leva à necessidade de um questionamento urgente do que é e do que deveria ser o âmbito da arte educação tanto em contextos formais como informais. 


\section{No Limiar de um Novo Conceito e Escola}

Em Portugal, no ensino das artes visuais no ensino básico e secundário usamos o termo Educação Visual, que foi escolhido desde os anos setenta, quando em Portugal se iniciavam as ideias da Educação pela Arte. Por Educação Visual entendemos uma área disciplinar que integra o estudo de contextos históricos e teóricos de análise e de produção de imagens sendo elas artísticas e do quotidiano, provenientes de culturas locais ou globais, integrando também processos de pensamento, reflexão crítica e criação, através da apreciação, criação e produção artística que pode ser multimodal e multitecnológica (EÇA; PASSARINHO; REIS, 2012) Nos textos elaborados para a Associação de Professores de Expressão e Comunicação Visual (APECV) por Aldo Passarinho, Ricardo Reis e eu própria, elaborámos algumas justificações chave para a permanência e a qualidade das artes visuais no currículo das escolas portuguesas. Considerámos que através da aquisição de saberes e competências próprias do pensamento visual, da expressão, da comunicação e da criação artística, os alunos e as alunas adquirem ferramentas críticas para se representarem e representarem a sociedade em que vivem. Nesses textos retomamos as ideias de Eisner e Efland, e declaramos que as artes ajudam as crianças e os jovens a aprender sobre si próprios e sobre as suas comunidades (EÇA et al., 2012). Através das artes os alunos preparam se para uma cidadania ativa e desenvolvem a sua personalidade, como membros de uma comunidade. Neste momento estou em crer, tal como muitas outras investigadoras em arte educação da Europa que urge refazer as justificações para a arte educação nas escolas; necessitamos de um discurso mais político que insira a arte educação no "[...] poder transformador da coletividade humana sobre o seu destino [...]" (JAMESON, 2001, p. 77). Necessitamos de uma arte educação para a sustentabilidade, para a liberdade de pensamento e de ação.

Quando falamos de artes, falamos de todas as artes e de artes contemporâneas relacionais, criadoras de relações dialógicas, artes como geradoras de interstícios relacionais capazes de tecerem comunidades educativas onde a aprendizagem se faz pelo processo artístico centrado no que se passa no mundo real, no quotidiano das vidas dos participantes neste processo educativo que é plural e deveria estar mais comprometido com os valores que fundeiam os estados democráticos que os nossos antepassados ajudaram a construir:

Vivese hoje a utopia no quotidiano subjetivo, no tempo real das experimentações concretas e deliberadamente fragmentarias. A obra de arte aparece como um interstício social no qual são possíveis essas experiências e essas novas possibilidades de vida: parece mais urgente inventar relações possíveis com os vizinhos de hoje do que entoar loas ao amanhã. (BOURRIAUD, 2009, p. 21). 


\section{Referências}

BOURRIAUD, N. Relational Aesthetics. Dijon: Les Presse du Reel, 2009.

COMISSÃO DAS COMUNIDADES EUROPEIAS. Memorando Sobre a Aprendizagem ao Longo da Vida. Bruxelas, 2000. Documento de trabalho dos serviços da Comissão. Disponível em: <http://dne. cnedu.pt/dmdocuments/Memorando\%20sobre\%20Aprendizagem\%20Longo\%20da\%20Vida\%20pt. pdf >. Acesso em: 21 ago. 2014.

DELORS, J. et al. Educação: um tesouro a descobrir. Porto: Ed. ASA, 1996.

EACAE. Arts and Cultural Education at School in Europe. Brussels, 2009. Disponível em: <http:// eacea.ec.europa.eu/education/eurydice/documents/thematic_reports/113en.pdf>. Acesso em: 21 ago. 2014.

EÇA, T.T.; PASSARINHO, A.; REIS, R. Textos em Construção. [Viseu]: APECV, 2012. Disponível em: <http://www.apecv.pt/pareceres/textosemcontrucao.pdf>. Acesso em: 21 ago. 2014.

JAMESON, F. A Cultura do Dinheiro: ensaios sobre a globalização. Tradução de Maria Elisa Cevasco e Marcos César de Paula Soares. Petrópolis: Ed. Vozes, 2001.

LAROSSA, J.B. Notas Sobre a Experiência e o Saber de Experiência. Revista Brasileira de Educação, n. 19, p. 2028, jan./abr. 2002.

LIVINGSTONE, S. The Changing Nature and Uses of Media Literacy. MEDIA@LSE Electronic Working Papers, no. 4, 2003. Disponível em: <http://eprints.lse.ac.uk/13476/1/The_changing_nature_and_ uses_of_media_literacy.pdf>. Acesso em: 6 out. 2010.

MILBRANDT, M; EÇA, T. T; HSIEH, K; SHIN, R., Relatório, apresentado na conferência mundial da InSEA, Melbourne, Austrália, 2014.

MORIN, E. Os Sete Saberes Necessários à Educação do Futuro. Brasil: Cortez Ed., 1999.

PINTO, M. (Coord.). Educação Para os Média em Portugal: experiências, actores e contextos. Lisboa: Entidade Reguladora para a Comunicação Social, 2011. Disponível em: <http://www. erc.pt/download/YToyOntzOjg6ImZpY2hlaXJvIjtzOjM4OiJtZWRpYS9Ic3R1ZG9zL29iamVjdG9fb2ZmbGluZS80Mi4XLnBkZiI7czo2OiJ0aXR1bG8iO3M6NTA6ImVzdHVkby1IZHVjYWNhby1wYXJhLW9zLW1IZGIhLWVtLXBvcnR1Z2FsLXZIcnNhby1wIjt9/estudo-educacao-para-os-media-em-portugal-versao-p>. Acesso em: 21 ago. 2014. 
RIBEIRO, I.P.F. Prática Pedagógica e Cidadania: uma interpretação crítica baseada na ideia de competência. Braga: Universidade do Minho, 2010.

SAldANHA, Â. No Caminho Para Casa. 2014. Tese (Doutorado em Educação Artística) - Faculdade de Belas Artes, Universidade do Porto, 2014, Porto, PT. (No prelo)

SELBY, D. Educación Global: hacia una irreducible perspectiva global en la escola. In: ANAUT, L. et al. Valores Escolares y Educación Para la Ciudadanía. Barcelona: Graó, 2002. P. 1327.

WINNER, E.; GOLDSTEIN, T.; VINCENTLANCRIN, S. Art for Art's Sake?: the impact of arts education. [Paris]: OECD Publ., 2013. (Serie Educational Research and Innovation)

Submetido para avaliação em 21 de setembro de 2014.

Aprovado para publicação em 15 de agosto de 2015. 